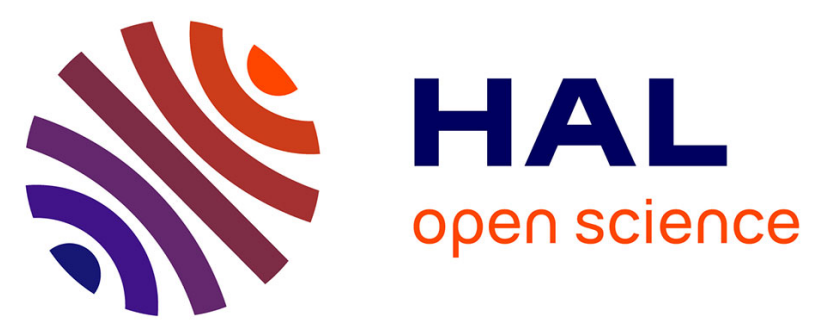

\title{
Impact of Gram-negative bacteria in interaction with a complex microbial consortium on biogenic amine content and sensory characteristics of an uncooked pressed cheese
}

Céline C. Delbes, Sylvie S. Pochet, Sandra S. Hélinck, Philippe P. Veisseire, Cécile C. Bord, Annick Lebecque, Monika M. Coton, Nathalie N. Desmasures, Emmanuel E. Coton, Francoise F. Irlinger, et al.

\section{- To cite this version:}

Céline C. Delbes, Sylvie S. Pochet, Sandra S. Hélinck, Philippe P. Veisseire, Cécile C. Bord, et al.. Impact of Gram-negative bacteria in interaction with a complex microbial consortium on biogenic amine content and sensory characteristics of an uncooked pressed cheese. Food Microbiology, 2012, 30 (1), pp.74-82. 10.1016/j.fm.2011.12.008 . hal-01000609

\section{HAL Id: hal-01000609 \\ https://hal.science/hal-01000609}

Submitted on 29 May 2020

HAL is a multi-disciplinary open access archive for the deposit and dissemination of scientific research documents, whether they are published or not. The documents may come from teaching and research institutions in France or abroad, or from public or private research centers.
L'archive ouverte pluridisciplinaire HAL, est destinée au dépôt et à la diffusion de documents scientifiques de niveau recherche, publiés ou non, émanant des établissements d'enseignement et de recherche français ou étrangers, des laboratoires publics ou privés. 


\title{
Impact of Gram-negative bacteria in interaction with a complex microbial consortium on biogenic amine content and sensory characteristics of an uncooked pressed cheese
}

\author{
Céline Delbès-Paus $^{\mathrm{a}, *}$, Sylvie Pochet ${ }^{\mathrm{b}}$, Sandra Helinck ${ }^{\mathrm{c}}$, Philippe Veisseire ${ }^{\mathrm{d}}$, Cécile Bord ${ }^{\mathrm{e}}$, \\ Annick Lebecque ${ }^{\mathrm{e}}$, Monika Coton ${ }^{\mathrm{f}, 1}$, Nathalie Desmasures ${ }^{\mathrm{g}}$, Emmanuel Coton ${ }^{\mathrm{f}, 1}$, \\ Françoise Irlinger $^{c}$, Marie-Christine Montel $^{\mathrm{a}}$ \\ a INRA, UR545 Recherches Fromagères, 20 Côte de Reyne, 15000 Aurillac, France \\ ${ }^{\mathrm{b}}$ INRA, UR342 Technologie et Analyses Laitières, 39800 Poligny, France \\ ' INRA AgroParisTech, UMR782 Génie et microbiologie des procédés alimentaires, 78850 Thiverval-Grignon, France \\ ${ }^{\mathrm{d}}$ Laboratoire de Biologie, Clermont Université, Université d'Auvergne, IUT Aurillac, BP 10448, F-63000 Clermont-Ferrand, France \\ e VetAgroSup, UR CALYTISS, 63370 Lempdes, France \\ ${ }^{\mathrm{f}}$ ADRIA Normandie, Bd du 13 juin 1944, 14310 Villers-Bocage, France \\ ${ }^{\mathrm{g}}$ Université de Caen Basse-Normandie, MILA E.A. 3213, IFR146 ICORE, Caen, France
}

\section{A R T I C L E I N F O}

\section{Article history:}

Received 4 May 2011

Received in revised form

9 November 2011

Accepted 6 December 2011

Available online 14 December 2011

\section{Keywords:}

Cheese

Gram-negative bacteria

Biogenic amine

Sensory characteristics

\begin{abstract}
A B S T R A C T
The impact of Gram-negative bacteria on sensory characteristics and production of volatile compounds as well as biogenic amines (BA) in the core of an uncooked pressed type model cheese was investigated in the presence of a defined complex microbial consortium. Eleven strains of Gram-negative bacteria, selected on the basis of their biodiversity and in vitro BA-production ability, were individually tested in a model cheese. Four out of 6 strains of Enterobacteriaceae (Citrobacter freundii UCMA 4217, Klebsiella oxytoca 927, Hafnia alvei B16 and Proteus vulgaris UCMA 3780) reached counts close to $6 \log$ CFU g ${ }^{-1}$ in the model cheese. In core of cheeses inoculated with Gram-negative bacteria, only slight differences were observed for microbial counts (Enterococcus faecalis or Lactobacillus plantarum count differences below $1 \log C F U g^{-1}$ ), acetate concentration (differences below $200 \mathrm{mg} \mathrm{kg}^{-1}$ ) and texture (greater firmness) in comparison to control cheeses. Cheese core colour, odour and volatile compound composition were not modified. Although ornithine, the precursor of putrescine, was present in all cheeses, putrescine was only detected in cheeses inoculated with $H$. alvei B16 and never exceeded $2.18 \mathrm{mmol} \mathrm{kg}^{-1}$ cheese dry matter. Cadaverine was only detected in cheeses inoculated with $H$. alvei B16, K. oxytoca 927, Halomonas venusta 4C1A or Morganella morganii 3A2A but at lower concentrations ( $<1.05 \mathrm{mmol} \mathrm{kg}^{-1}$ cheese dry matter), although lysine was available. Only insignificant amounts of the detrimental BA histamine and tyramine, as well as isopentylamine, tryptamine or phenylethylamine, were produced in the cheese model by any of the Gram-negative strains, including those which produced these BA at high levels in vitro.
\end{abstract}

(C) 2011 Elsevier Ltd. All rights reserved.

\section{Introduction}

Microbial diversity in raw milk including yeasts, moulds, Gram-positive and Gram-negative bacteria is a core element in the cheese-making process. It is needed to maintain sensory quality and diversity while ensuring microbiological safety. In raw milk, a wide

\footnotetext{
* Corresponding author. Tel.: +33 4714564 19; fax: +33 471456413 .

E-mail address: celine.delbes@clermont.inra.fr (C. Delbès-Paus).

1 Present address: Université de Brest, UEB, EA3882, Laboratoire Universitaire de Biodiversité et Ecologie Microbienne, IFR148 ScInBioS, ESMISAB, Technopôle de Brest Iroise, 29280 Plouzané, France.
}

range of Gram-negative bacteria (Lafarge et al., 2004) was found at relatively high population levels (up to $10^{5} \mathrm{CFU} \mathrm{ml}^{-1}$ ) (Ercolini et al., 2009; Munsch-Alatossava and Alatossava, 2006). In a study by Coton et al. (2012), among 173 Gram-negative strains isolated from milks and various cheeses, 68 Gram-negative species were identified and nearly half belonged to the Enterobacteriaceae family. Enterobacteriaceae counts can reach $10^{6}-10^{7} \mathrm{CFU} \mathrm{g}{ }^{-1}$ in the core of uncooked pressed cheeses during the first days of ripening and then slowly decrease until the end of ripening (Pintado et al., 2008; Tornadijo et al., 2001). In the cores of hard or uncooked pressed cheeses such as Pecorino, Saint-Nectaire or San Simón, they represented from $14 \%$ to $56 \%$ of the isolates (Chaves-Lopez et al., 2006; 
Delbes et al., 2007; Tornadijo et al., 2001). On the surface of European smear cheeses, Gram-negative bacteria were shown to account for $18-60 \%$ of bacterial isolates (Larpin-Laborde et al., 2011; Mounier et al., 2005; Maoz et al., 2003).

The actual contribution of Gram-negative bacteria in regards to the development of organoleptic characteristics in cheese is still unclear. Most Gram-negative bacteria in cheese are considered as spoilage flora as they can be responsible for defects in cheese texture and flavour (Sørhaug and Stepaniak, 1997). However, some species were found to influence organoleptic properties; for example one Proteus vulgaris strain was found to produce significant amounts of volatile compounds in a model cheese medium (Deetae et al., 2009b) and some Hafnia alvei strains can be used as ripening agents (Alonso-Calleja et al., 2002).

High counts of Enterobacteriaceae are considered indicative of poor hygienic quality in milking and cheese-making processes but the safety status of most food-borne Gram-negative bacteria is poorly documented. One aspect of the risks associated with cheese bacteria concerns their ability to form biogenic amines (BA). Enterobacteriaceae may produce BA in cheese which may be detrimental to consumer health (Marino et al., 2000; Martuscelli et al., 2005). Cheese-associated strains of Citrobacter freundii, H. alvei, Morganella morganii, Klebsiella oxytoca, Enterobacter sp. and Serratia liquefaciens have been found to produce significant amounts of BA in vitro (Coton et al., 2012; Marino et al., 2000; Pattono et al., 2008). In the study by Coton et al. (2012), cadaverine was the most frequent BA produced in vitro, followed by isoamylamine, histamine and putrescine. However, the ability to form biogenic amines in vitro may not reflect their actual production in cheese. In this context, cadaverine was frequently found in variable amounts in blue cheeses (up to $1.86 \mathrm{mmol} \mathrm{kg}^{-1}$ ) (Marino et al., 2000), hard cooked cheeses (Bütikofer et al., 1990) as well as in uncooked pressed cheeses (up to $6 \mathrm{mmol} \mathrm{kg}^{-1}$ in Asino cheese), especially cheeses with high Enterobacteriaceae counts (Innocente et al., 2009; Pintado et al., 2008; Schirone et al., 2011; Schneller et al., 1997). Indeed, even within a cheese type, environmental and microbiological factors can influence BA-production (Buňková et al., 2010).

The aim of the present work was to develop a methodology to evaluate the potentialities and risks associated with Gram-negative bacteria within uncooked pressed cheese ecosystems, in terms of cheese sensory characteristics and biogenic amines production. An uncooked pressed type cheese prepared with a defined microbial consortium and validated as a model favorable to the growth of Gram-negative bacteria, was used to investigate the impact in the cheese core of 11 strains of Gram-negative bacteria selected from the collection studied by Coton et al. (2012). Microbial growth, sensory characteristics, production of organic acids, volatile compounds and biogenic amines in cheese in the presence of each Gram-negative strain were assessed.

\section{Materials and methods}

\subsection{Model cheese manufacture and ripening}

Pasteurized milk $\left(72{ }^{\circ} \mathrm{C}, 20 \mathrm{~s}\right)$ was used to prepare $500 \mathrm{~g}$ model cheeses using an uncooked pressed cheese process. The entire cheese-making process was carried out using sterile tools and equipment. Milk was placed into vats and warmed up to $33^{\circ} \mathrm{C}$. The starter culture Streptococcus salivarius ssp. thermophilus 1a was isolated from the MY800 commercial starter culture (Rhodia S.A., Paris La Défense, France) commonly used to prepare uncooked pressed cheeses. It was inoculated in all vats $\left(\sim 10^{7} \mathrm{CFU} \mathrm{ml}^{-1}\right)$. A technological consortium (see Section 2.2) was also added to all vats at a concentration of $10^{3} \mathrm{CFU} \mathrm{ml} \mathrm{m}^{-1}$ and $10^{2} \mathrm{CFU} \mathrm{ml}{ }^{-1}$ for each bacterial and yeast strain, respectively. Rennet was added to all vats at
$1.51 \mathrm{~g} \mathrm{l}^{-1}$ (Beaugel $520 \mathrm{mg} \mathrm{l}^{-1}$ of chymosin). Coagulation proceeded for approximately $45 \mathrm{~min}$ and then the curd was cut, prepressed and placed in molds. Salt ( $2 \%$ of dry matter) was added and the curd was drained under 3-bar pressure for $24 \mathrm{~h}$. The cheeses were coated with wax containing $1000 \mathrm{ppm}$ of natamycin (Coquard, Villefranche sur Saône, France) to prevent the development of moulds and yeasts on the cheese surface. They were then ripened in sterile stainless steel boxes in a ripening room at $9{ }^{\circ} \mathrm{C}$ for 28 days. Samples of milk were taken aseptically from each vat prior to the addition of the rennet as well as samples from the cheeses (corresponding to one half of each cheese) were taken on days $1,8,18$ and 28 . The cheese rind (5 mm thick) was discarded. Subsamples were stored either at $-80^{\circ} \mathrm{C}$ for volatile aroma compounds analysis or at $-20^{\circ} \mathrm{C}$ for further microbiological tests and determination of biochemical parameters (organic acids, free amino acids index and biogenic amine profile).

\subsection{Microbial strains}

The technological consortium consisted of 8 bacteria (Lactococcus lactis Tan4, Enterococcus faecalis SB1, Lactobacillus plantarum FH3, Leuconostoc mesenteroides MSE7, Str. salivarius spp. thermophilus MY800 1a, Arthrobacter arilaitensis Mu107, Corynebacterium casei CRBM9, Staphylococcus equorum RPF6) and 2 yeasts (Debaryomyces hansenii OGA10, Yarrowia lipolytica Sn4Co3). It was chosen to mimic a representative community comprising the major microbial groups commonly found in raw milk cheese. The strains were selected depending on their ability to develop together in the model cheese as determined in preliminary trials (data not shown). All strains were obtained from the INRA UR545 collection (Aurillac, France), except for Mu107 (INRA UMR782, Thiverval-Grignon, France).

Eleven Gram-negative strains originating from the work collection studied by Coton et al. (2012) (Table 1) were selected on the basis of species biodiversity and risk factors determined in vitro, in particular BA production (Table 3; Coton et al., 2012; Imran et al., pers. com.), as well as for their ability to grow together in presence of the technological consortium in the model cheese in preliminary trials (data not shown). Thus, eight strains that clearly became established in the cheese core during ripening (PCA Q6.3, CV 30.6, UCMA 4217, 3A2A, 927, B16, UCMA 3780, 4C1A) and three strains whose establishing was doubtful (B39, Pi18, PCAi D6.5) were selected for the experiment. They came from the INRA UR545 collection (PCA Q6.3, CV 30.6, Pi18, PCAi F2.5), INRA UMR782 collection (B16, B39, 3A2A, 4C1A), University of Caen - MILA collection (UCMA 3780, UCMA 4217) or Aérial collection, Illkirch, France (927). They were grown in Brain Heart Infusion medium incubated at $30^{\circ} \mathrm{C}$ for $24 \mathrm{~h}$. All Grampositive and Gram-negative bacteria and yeast pure strains were stored in 5\%-glycerol semi-skimmed UHT milk at $-80^{\circ} \mathrm{C}$ until use.

\subsection{Experimental design}

In all cheese-making experiments, the tested Gram-negative strain was inoculated into milk at a concentration of $10^{3} \mathrm{CFU}$ $\mathrm{ml}^{-1}$. Milk batches inoculated only with the technological consortium were included in each experiment on each day of manufacture (control cheeses).

\subsubsection{Experiment 1: impact of Gram-negative strains at the end of cheese ripening}

A unique model cheese was made with each of the 11 Gramnegative strains on the same day and the trial was replicated once two days later. Microbial counts as well as profiles for organic acids, volatile compounds and biogenic amines were determined, and sensory analyses performed, on the core of the model cheese at the end of ripening (28 days). Six Gram-negative strains that reached the highest counts and/or were BA-producers in cheese 
Table 1

Counts and effect of Gram-negative strains on microbial counts and organic acids in model cheese core after 28 days (experiment 1 ).

\begin{tabular}{|c|c|c|c|c|c|c|c|c|c|c|c|c|c|}
\hline \multirow[t]{3}{*}{ Strain } & \multirow[t]{3}{*}{ Species } & \multirow[t]{3}{*}{ Family } & \multirow{3}{*}{$\begin{array}{l}\text { Gram negative } \\
\text { counts }^{\mathrm{a}}\end{array}$} & \multirow{3}{*}{$\begin{array}{l}\text { Cheese } \\
\text { class }^{\text {b }}\end{array}$} & \multicolumn{9}{|c|}{ Microbial counts and organic acids per cheese class ${ }^{\mathrm{a}}$} \\
\hline & & & & & \multicolumn{3}{|c|}{ E. faecalis (SB) } & \multicolumn{3}{|c|}{ Lb. plantarum $(\mathrm{FH})$} & \multicolumn{3}{|c|}{ Acetate } \\
\hline & & & & & Mean & SD & & Mean & SD & & Mean & SD & \\
\hline UCMA 4217 & Citrobacter freundii & Enterobacteriaceae & 7.1 & 1,1 & & & & & & & & & \\
\hline 927 & Klebsiella oxytoca & Enterobacteriaceae & 5.5 & 1,1 & 6.34 & 0.32 & a & 7.19 & 0.30 & $\mathrm{~b}$ & 2.20 & 0.18 & c \\
\hline B16 & Hafnia alvei 1 & Enterobacteriaceae & 6.5 & 1,1 & & & & & & & & & \\
\hline PCA Q6.3 & Pantoea agglomerans & Enterobacteriaceae & 3.2 & 1,2 & & & & & & & & & \\
\hline Pi18 & Chryseobacterium sp. close to C. bovis & Flavobacteriaceae & $<2$ & 1,2 & & & & & & & & & \\
\hline $3 \mathrm{~A} 2 \mathrm{~A}$ & Morganella morganii & Enterobacteriaceae & 3.0 & 2,2 & 6.08 & 0.24 & a & 6.08 & 0.20 & $\mathrm{a}$ & 1.57 & 0.34 & a \\
\hline $4 \mathrm{C} 1 \mathrm{~A}$ & $\begin{array}{l}\text { Halomonas } \\
\text { venusta/alkaliphila/hydrothermalis }\end{array}$ & Halomonadaceae & 3.2 & 2,3 & & & & & & & & & \\
\hline B39 & Halomonas sp. & Halomonadaceae & $<2$ & 3,3 & & & & & & & & & \\
\hline UCMA 3780 & Proteus vulgaris & Enterobacteriaceae & 4.0 & 3,3 & & & & & & & & & \\
\hline CV30.6 & Pseudomonas putida & Pseudomonadaceae & 3.0 & 3,3 & 6.87 & 0.25 & b & 7.05 & 0.31 & $\mathrm{~b}$ & 1.85 & 0.18 & $\mathrm{~b}$ \\
\hline PCAi D6.5 & Stenotrophomonas maltophilia & Xanthomonadaceae & $<2$ & 3,3 & & & & & & & & & \\
\hline \multirow[t]{2}{*}{ Control } & No Gram-negative strain added & & $<2$ & 3,3 & & & & & & & & & \\
\hline & & & & & $* * *$ & & & $* * *$ & & & $* *$ & & \\
\hline
\end{tabular}

${ }^{\text {a }}$ Counts in $\log \mathrm{CFU} \mathrm{\textrm {g } ^ { - 1 }}$, organic acid concentrations in $\mathrm{g}$ per $\mathrm{kg}$ of cheese. Only the microbial groups and organic acids for which a significant effect of cheese class was observed are indicated in the table. SB: Slanetz and Bartley agar. FH: facultatively heterofermentative lactobacilli agar.

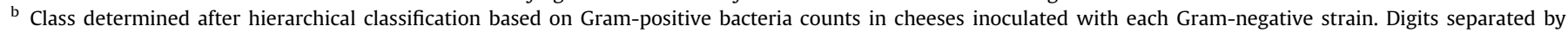

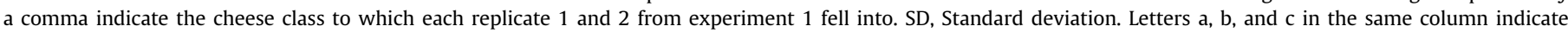
homogeneous statistical processing groups that were significantly different at $P<0.1^{*}, P<0.05^{* *}$ or $P<0.01^{* * *}$ according to the Newman Keuls test, with a $<$ b

(UCMA 4217, 3A2A, 927, B16, UCMA 3780, 4C1A), were selected for the next experiment.

\subsubsection{Experiment 2: kinetic impact of Gram-negative strains}

These six strains (UCMA 4217, B16, UCMA 3780, 3A2A, 927 and 4C1A) were individually tested in cheese at two-day intervals. Three model cheeses were made per tested strain on the same day. Evolution of microbial counts and organic acids as well as BA concentrations in the cheese core were determined at day $1,8,18$ and 28 while the volatile compound profile was analyzed only at the end of ripening (28 days).

\subsection{Cheese analyses}

\subsubsection{Microbial analyses}

Str. salivarius ssp. thermophilus, Lc. lactis, Lb. plantarum, Ln. mesenteroides, E. faecalis and yeast populations were enumerated under the conditions described by Callon et al. (2005), on the following agar media respectively: M17, Turner-Sandine-Elliker (TSE), facultatively heterofermentative lactobacilli (FH), Mayeux-Sandine-Elliker (MSE), Slanetz and Bartley (SB) and oxytetracyclin-glucose (OGA). Grampositive catalase-positive bacteria ( $A$. arilaitensis, C. casei, S. equorum) and $E$. faecalis were enumerated on Cheese Ripening Bacteria Medium (CRBM) as described by Denis et al. (2001) and on Rabbit Plasma Fibrinogen Agar (RPFA) (EN ISO 6888-2). To discriminate between these four species, isolates (approx. 10 colonies, including at least two of each colony morphotype, per CRBM and RPFA plate, at each ripening time) were checked for their ability to grow on $\mathrm{BHI}$ agar in the presence of five selective agents as described by Deetae et al. (2009a). Gramnegative bacteria were enumerated on Plate Count Agar supplemented with $1 \%$ milk, $5 \mathrm{mg} \mathrm{l}^{-1}$ vancomycin and $5 \mathrm{mg} \mathrm{l}^{-1}$ crystal violet as inhibitors of Gram-positive bacteria (PCAI) (Delbes et al., 2007) and incubated at $30^{\circ} \mathrm{C}$ for $48 \mathrm{~h}$ as well as on cetrimide-fucidincephalosporin (CFC) agar. All media were purchased from Biokar Diagnostics (Pantin, France). Milk and cheese pH values were determined with a 926 VTV pH meter with an Ingold 406 MX penetration electrode (Mettler-Toledo S.A., Viroflay, France).

\subsubsection{Determination of organic acid concentrations}

Concentrations of citric, malic, succinic, lactic, fumaric, acetic and propionic acids, which are commonly found in milk and cheeses, were determined. Cheese samples $(5 \mathrm{~g})$ were homogenized for
$2 \mathrm{~min}$ in $10 \mathrm{~mL}$ distilled water with an Ultra-Turax (9500 rpm). After incubation at $50^{\circ} \mathrm{C}$ for $2 \mathrm{~h}$, the suspensions were homogenized again (Ultra-Turax). Samples were then deproteinized by mixing with $5 \mathrm{~mL}$ trichloracetic acid $24 \%$ and allowed to stand for $1 \mathrm{~h}$ before centrifugation at $40000 \times \mathrm{g}$ for $20 \mathrm{~min}$ at $4{ }^{\circ} \mathrm{C}$. Supernatants were filtered through $0.20 \mu \mathrm{m}$ pore-size filters (PTFE). Organic acids were separated isocratically by high-performance liquid chromatography (HPLC) (Dionex, France) on a cation-exchange column (Aminex HPX-87, Bio-Rad, Marnes-la-Coquette, France) maintained at $35^{\circ} \mathrm{C}$ (Oven LC30) under $0.6 \mathrm{~mL} \mathrm{~min}^{-1}$ of sulfuric acid (0.01 N) (GP50 gradient pump). Detection was done at $210 \mathrm{~nm}$ (UVD 170S). Results were expressed in mg per $\mathrm{kg}$ of cheese.

\subsubsection{Sensory analyses}

Twelve trained assessors compared the colour (lightness), odour (overall intensity) and texture (softness to the touch) of trial cheeses inoculated with each of the $11 \mathrm{Gram}$-negative strains (experiment 1 ) to those of control cheeses ( 24 cheeses in total) in 44 blind triangular differences tests (ISO 4120). For each triangular test, either the assay or the control cheese sample was doubled. The assessors had to indicate which sample was different from the other two and to make comments on perceived sensations. Percentages of sensory term citations among the assessors were calculated. At least 24 responses were required for each test. All samples were served at $15 \pm 2{ }^{\circ} \mathrm{C}$. Two replicates were tested for each cheese sample.

\subsubsection{Volatile aroma compounds analysis}

Analyses of volatile compounds were carried out at the end of ripening on cheese samples from experiments 1 and 2 using dynamic headspace extraction, gas chromatography and mass selective detection, as described by Sympoura et al. (2009). One gram of cheese was rapidly homogenized with $9 \mathrm{~g}$ of anhydrous sodium sulfate $\left(\mathrm{Na}_{2} \mathrm{SO}_{4}\right)$ in a mortar. Four grams of the powdery mixture was placed on $0.2 \mathrm{~g}$ of glass wool in a cylindrical glass extraction cartridge $(28 \mathrm{~mm}$ diameter $\times 47 \mathrm{~mm}$ height; Etablissements Maillières Frères, Aubière, France). Dynamic headspace extraction was performed using Tekmar apparatus (TelmarDohrmann, Cincinnati, OH). An Agilent 5890 gas chromatograph (Agilent Technologies, Palo Alto, CA), equipped with a DB MS capillary column $(30 \mathrm{~m} \times 0.32 \mathrm{~mm}$ i.d. $\times 1 \mu \mathrm{m}$, J\&W Scientific, Agilent Technologies) was used for the analysis of volatile compounds with a MSD HP 5973 mass selective detector. The chromatography 
parameters were the same as described by Sympoura et al. (2009). However, the oven temperature was programmed as follows: 9 min isothermal at $5{ }^{\circ} \mathrm{C}, 4^{\circ} \mathrm{C} \mathrm{min}-1$ increasing to $215^{\circ} \mathrm{C}$. All volatile compounds were identified according to the comparison of their mass spectra with those obtained from two databanks (Wiley $275 \mathrm{~K}$ and NBS 75k). Peak absolute areas (arbitrary units) were calculated from the total ion current (TIC).

\subsubsection{Free amino acids and biogenic amines determination}

The overall concentration of free amino acids (FAA) was evaluated using a cadmium-ninhydrine colorimetric assay determined on the water soluble fraction of the cheese core (Folkertsma and Fox, 1992). The FAA index was expressed as mmoles glycine equivalent in $100 \mathrm{~g}$ dry matter, as glycine was used instead of leucine for the calibration curve. Samples were analyzed twice on two different days. Two colorimetric assays were performed on each water soluble fraction.

Free amino acids were analyzed in cheese extracts by HPLC. Cheese extracts were prepared as described by Yvon et al. (1998). Amino acids were then analyzed by HPLC after a derivatization procedure. Briefly, derivatization was carried out on a mixture of $400 \mu$ l of cheese filtrate, $40 \mu \mathrm{l}$ of internal standard consisting of NorLeucine $\left(0.3 \mathrm{gl}^{-1}\right)$ and $560 \mu \mathrm{l}$ of MilliQ water. To $10 \mu \mathrm{l}$ of the above solution, $70 \mu \mathrm{l}$ of borate buffer and $20 \mu \mathrm{l}$ of AQC reagent (6-Aminoquinolyl-N-hydroxysuccinimidyl carbamate) were mixed and then placed at $55^{\circ} \mathrm{C}$ for $10 \mathrm{~min}$. The amino acids were analyzed by reverse phase HPLC on a NovaPack C18 column $(3.9 \mathrm{~mm} \times 150 \mathrm{~mm})$ by using a fluorescence detector (UltiMate 3000 Fluorescence detector, Dionex) with $\lambda_{\mathrm{ex}}$ $250 \mathrm{~nm}$ and $\lambda_{\mathrm{em}} 395 \mathrm{~nm}$. The flow rate was $1 \mathrm{ml} \mathrm{min}^{-1}$ and the elution was done at $37^{\circ} \mathrm{C}$. Eluant A was an AccQ.Tag buffer (Waters) and eluant B was acetonitrile. The elution started with $100 \%$ of eluant A and the ratio of eluant B was increased from 0 to $17 \%$ over $39 \mathrm{~min}$. The concentration of each amino acid was determined from a standard curve.

Nine BA (tryptamine, 2-phenylethylamine, isopentylamine, putrescine, cadaverine, histamine, tyramine, spermidine and spermine) were analyzed in cheese cores after dansyl derivation and separation by reverse phase high-performance-liquidchromatography (Dionex, France) (Bütikofer et al., 1990). The identity of the peaks was determined by comparing their retention times and spectral profiles (diode array detection) to those of standard molecules analyzed in the same conditions. Samples were analyzed twice on two different days.

\subsection{Statistical analyses}

All statistical analyses were performed with the Statistica software (version 6; Statsoft, Maisons-Alfort, France). Microbial count data from the duplicate 28-day old cheeses from experiment 1 were subjected to principal-component analysis followed by an ascending hierarchical classification (AHC) analysis and by K-means clustering, in order to determine classes of cheeses inoculated with the various Gram-negative strains. The data (microbial counts, organic acids and volatile compound concentrations) were then processed by monofactorial (cheese classes defined by AHC) variance analysis (ANOVA). Data from experiment 2 (triplicate dataset of microbial counts and organic acid concentrations in cheeses on day $1,8,18$ and 28 ) were subjected to repeated measures (four sampling dates) ANOVA to assess the effect of inoculation with Gram-negative strains on microbial counts and organic acid concentrations in cheeses over the whole ripening period. Biogenic amine concentration data in 28-day old cheeses from experiments 1 and 2 were processed by monofactorial (biogenic amineproducing Gram-negative strain) ANOVA. In those comparisons where a significant effect after any variance analysis was observed, differences between means were tested using a Newman-Keuls test.

\section{Results}

\subsection{Counts of Gram-negative bacteria in the core of the model} cheese

The 11 selected Gram-negative strains were individually tested in the cheeses (experiment 1, Table 1). Gram-negative bacteria counts after 28 days were below the detection level $\left(2 \log \mathrm{CFU} \mathrm{g}{ }^{-1}\right)$ in control cheeses as well as in cheeses inoculated with Halomonas sp. B39, Chryseobacterium sp. Pi18 or Stenotrophomonas maltophilia PCAI D6.5 (Table 1). Average counts in cheeses inoculated with Pantoea agglomerans PCA Q6.3, Pseudomonas putida CV 30.6, Halomonas venusta $4 \mathrm{C} 1 \mathrm{~A}$, or $M$. morganii $3 \mathrm{~A} 2 \mathrm{~A}$ were similar, around $3 \log$ CFU g ${ }^{-1} \pm 0.5 \log$. They were highest in the cases of addition of P. vulgaris UCMA 3780 ( 4 log CFU g ${ }^{-1}$ ), K. oxytoca 927 (5.5 log CFU $\left.\mathrm{g}^{-1}\right), H$. alvei $\mathrm{B} 16\left(6.5 \log \mathrm{CFU} \mathrm{g}{ }^{-1}\right)$ and C. freundii UCMA 4217 $\left(7.1 \log\right.$ CFU g ${ }^{-1}$ ) (Table 1$)$.

The four strains that reached the highest counts at 28 days (C. freundii UCMA 4217, K. oxytoca 927, H. alvei B16 and P. vulgaris UCMA 3780) were selected for the second experiment. Among the remaining strains, the two strains that produced biogenic amines in cheese in the first experiment (M. morganii 3A2A and $H$. venusta 4C1A, see below) were also selected. Their growth was monitored during cheese ripening (Fig. 1). K. oxytoca 927 reached the highest levels of all strains (around $7.4 \log \mathrm{CFU} \mathrm{g}{ }^{-1}$ ) in the cheese core on day 1 but then slightly decreased and stabilized to around $6 \log \mathrm{CFU} \mathrm{g}{ }^{-1}$ from day 18 until the end of ripening. The growth of $H$. alvei B16 was lower at the beginning ( $6.7 \log \mathrm{CFU} \mathrm{g}{ }^{-1}$ on day 8 ) then it reached a $0.8 \log$ higher level in comparison to any of the other Gram-negative strains on days 18 and 28. P. vulgaris UCMA 3780 and C. freundii UCMA 4217 stabilized at an intermediary level of $5.7 \log \mathrm{CFU} \mathrm{g}{ }^{-1}$ from day 1 until the end of ripening. Finally, the levels of $H$. venusta $4 \mathrm{C} 1 \mathrm{~A}$ and $M$. morganii 3A2A remained close to $5.5 \log \mathrm{CFU} \mathrm{g}^{-1}$ from day 1 to day 18 but had dropped to below $4 \log$ CFU g ${ }^{-1}$ by day 28 .

Although $P$. vulgaris UCMA 3780 counts in 28-day cheese were lower in experiment $1\left(4 \log \mathrm{CFU} \mathrm{g}{ }^{-1}\right)$ than in experiment $2(5.7 \mathrm{log}$ $\left.\mathrm{CFU} \mathrm{g}^{-1}\right)$, and conversely $C$. freundii UCMA 4217 counts were higher in experiment $1\left(7.1 \log \mathrm{CFU} \mathrm{g}{ }^{-1}\right)$ than in experiment $2\left(5.7 \log \mathrm{CFU} \mathrm{g}{ }^{-1}\right)$, the four Enterobacteriaceae C. freundii UCMA 4217, K. oxytoca 927, H. alvei B16 and P. vulgaris UCMA 3780 showed the highest counts of the tested Gram-negative strains in both experiments.

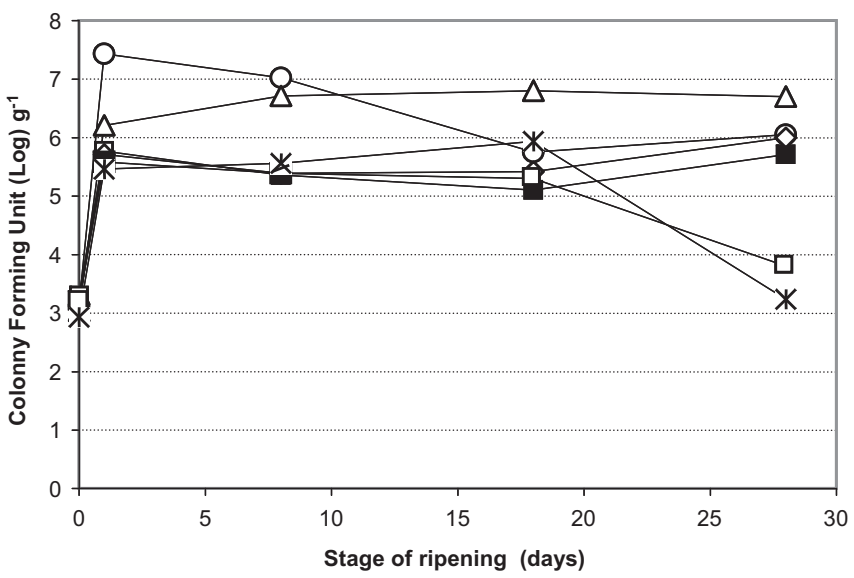

Fig. 1. Gram-negative counts ( $\log \mathrm{CFU} \mathrm{g}{ }^{-1}$ ) during ripening (experiment 2 ) in cheeses inoculated with $K$. oxytoca $927(O)$, H. alvei B16 $(\triangle)$, C. freundii UCMA $4217(\boldsymbol{\square})$, P. vulgaris UCMA $3780(\diamond)$, M. morganii 3A2A $(\square)$, H. venusta 4 C1A $(\times)$. Values are the means of 3 cheeses at each different ripening stage. For greater clarity, error bars are not included. 


\subsection{Impact of Gram-negative bacteria on microbial counts and organic acid concentrations}

After 28 days of ripening, the different cheeses inoculated with one of the 11 Gram-negative strains (experiment 1), clustered in three classes in an ascending hierarchical classification based on microbial counts (Gram-positive bacteria and yeasts) (Table 1). Control cheeses fell into class 3. Class 1 clustered cheeses which showed significantly lower counts in E. faecalis than the class 3 cheeses, higher counts of $L b$. plantarum than the class 2 cheeses and the highest concentrations of acetate. Cheeses in class 2 showed lower counts of E. faecalis than the class 3 cheeses, the lowest counts of $L b$. plantarum as well as the lowest concentrations of acetate. No difference in neither any other microbial population count nor any other organic acid concentration was detected between classes (data not shown). Both duplicate cheeses inoculated with Halomonas B39, P. putida CV 30.6, P. vulgaris UCMA 3780 or S. maltophilia PCAi D6.5 clustered in class 3 along with the control cheeses. Both cheeses inoculated with $C$. freundii UCMA 4217, K. oxytoca 927 or H. alvei B16 clustered in class 1 . Cheeses inoculated with M. morganii 3A2A fell into class 2 .

Microbial counts and organic acid concentration data from 1, 8, 18 and 28-day old cheeses from experiment 2 were subjected to repeated ANOVA measures. Table 2 sums up the significant effects induced by inoculation with different Gram-negative strains over the entire ripening period. In particular, cheeses inoculated with C. freundii showed lower counts for E. faecalis and to a lesser extent for $L b$. plantarum than control cheeses. Cheeses inoculated with $P$. vulgaris showed lower counts for $S$. equorum, Lb. plantarum than control cheeses. Cheeses inoculated with Halomonas 4C1A showed higher counts for E. faecalis and lower amounts of acetate than control cheeses. Cheeses inoculated with M. morganii showed the lowest counts for $L b$. plantarum. Finally, cheeses inoculated with $K$. oxytoca showed the highest amounts of acetate and the lowest amounts of citrate. No significant difference was observed between the control cheeses and cheeses inoculated with $H$. alvei.

Hence, in both experiments 1 and 2, cheeses inoculated with C. freundii showed lower counts for $E$. faecalis than control cheeses, those inoculated with M. morganii showed the lowest counts for $L b$. plantarum and the lowest amounts of acetate and those inoculated with $K$. oxytoca showed the highest amounts of acetate. P. vulgaris (UCMA 3780) only had a significant effect on microbial counts in cheeses from experiment 2 , where this strain reached a higher count. However, even when significant, most differences in microbial counts or organic acid concentrations between cheeses inoculated with Gram-negative bacteria and control cheeses can be considered low (below $1 \log$ CFU g ${ }^{-1}$ and below $200 \mathrm{mg} \mathrm{kg}^{-1}$ for acids).

\subsection{Effect of Gram-negative bacteria on sensory characteristics and volatile compounds}

According to the results obtained after the sensory analyses (experiment 1 , triangular tests), each assay cheese was significantly different $(p<5 \%)$ from the control cheeses after 28 days of ripening (data not shown). Cheese texture was the main difference observed with assay cheese firmness considered different to that of the control cheeses (to various extents depending on the strain considered). Cheeses inoculated with $H$. alvei B16, M. morganii 3A2A or $H$. venusta $4 \mathrm{C} 1 \mathrm{~A}$ were cited as firmer than control cheeses by 79 , 71 , and $69 \%$ of the trained assessors respectively. Inoculation with Halomonas sp. (B39), Chryseobacterium sp. (Pi18), S. maltophilia (PCAI D6.5), P. agglomerans (PCA Q6.3), P. putida (CV 30.6), P. vulgaris (UCMA 3780), or C. freundii (UCMA 4217) showed increased cheese firmness for 51 to $64 \%$ of assessors. Finally, cheeses inoculated with K. oxytoca 927 were only cited as firmer by $43 \%$ of the assessors. Concerning cheese odour, the assessors detected a change in odour only for cheeses inoculated with P. vulgaris UCMA 3780. Indeed, a less instense odour was detected by $47 \%$ of the assessors for the two cheese replicates analyzed in comparison to control cheeses. Volatile compounds were isolated from model cheeses from experiments 1 and 2 at day 28 of ripening by dynamic headspace. A limited number (26) of volatile compounds were detected. They belonged to 5 chemical families (ketones, alcohols, esters, aldehydes and terpenes). Volatile sulphur compounds were not detected or were present only as traces. The main compounds isolated from cheese headspaces were 3-hydroxy-2-butanone, 3-methyl-1- butanol, 1-butanol, ethyl caprylate, ethyl butyrate, ethyl caproate, hexanal, nonanal and heptanal. There were no qualitative or quantitative differences in the volatile compounds identified in any of the model cheeses (controls and assays). Overall, the Gram-negative bacteria did not markedly affect the core colour or odour of the model cheese and in the majority of cases only slightly affected its texture.

\subsection{Production of biogenic amines by Gram-negative bacteria in model cheese}

BA profiles were determined in cheeses from experiments 1 and 2 . At 28 days of ripening, all the analyzed amines except tryptamine were detected in each of the experimental cheeses including

Table 2

Microbial counts and organic acid concentrations over the whole ripening period in cheeses inoculated with Gram-negative strains (experiment 2).

\begin{tabular}{|c|c|c|c|c|c|c|c|c|c|c|c|c|c|c|c|c|}
\hline & \multirow[t]{2}{*}{ Strain } & \multicolumn{3}{|c|}{ E. faecalis (SB) } & \multicolumn{3}{|c|}{ Lb. plantarum $(\mathrm{FH})$} & \multicolumn{3}{|c|}{ S. equorum (RPF) } & \multicolumn{3}{|c|}{ Acetate } & \multicolumn{3}{|c|}{ Citrate } \\
\hline & & Mean & SD & & Mean & SD & & Mean & SD & & Mean & SD & & Mean & SD & \\
\hline C. freundii & UCMA 4217 & 5.33 & 0.21 & $\mathrm{a}$ & 5.86 & 0.69 & $\mathrm{~b}$ & 3.71 & 0.17 & $\mathrm{~b}$ & 1111 & 850 & & 915 & 429 & $\mathrm{~b}$ \\
\hline H. alvei & B16 & 5.54 & 0.25 & b & 6.10 & 0.91 & c & 3.79 & 0.47 & b & 1166 & 859 & & 811 & 541 & $a b$ \\
\hline P. vulgaris & UCMA 3780 & 5.71 & 0.23 & b & 5.66 & 0.65 & a & 2.20 & 1.10 & a & 1073 & 860 & & 903 & 469 & $\mathrm{~b}$ \\
\hline Control & & $\begin{array}{l}5.72 \\
* *\end{array}$ & 0.34 & $\mathrm{~b}$ & $\begin{array}{l}6.02 \\
* *\end{array}$ & 0.74 & c & $\begin{array}{l}3.89 \\
*\end{array}$ & 0.26 & $\mathrm{~b}$ & $\begin{array}{l}1201 \\
\text { NS }\end{array}$ & 931 & & $\begin{array}{l}667 \\
*\end{array}$ & 571 & a \\
\hline H. venusta & $4 \mathrm{C} 1 \mathrm{~A}$ & 5.43 & 0.69 & $\mathrm{~b}$ & 5.98 & 0.93 & b & 4.08 & 1.10 & & 940 & 726 & a & 769 & 350 & $\mathrm{~b}$ \\
\hline M. morganii & $3 \mathrm{~A} 2 \mathrm{~A}$ & 5.15 & 0.52 & a & 5.62 & 0.56 & a & 4.17 & 0.57 & & 925 & 695 & a & 742 & 340 & $\mathrm{~b}$ \\
\hline K. oxytoca & 927 & 4.99 & 0.54 & $\mathrm{a}$ & 5.92 & 0.91 & ab & 3.92 & 0.48 & & 1212 & 888 & c & 600 & 451 & $\mathrm{a}$ \\
\hline Control & & $\begin{array}{l}5.07 \\
* *\end{array}$ & 0.45 & a & $\begin{array}{l}5.86 \\
*\end{array}$ & 0.71 & ab & $\begin{array}{l}3.85 \\
\text { NS }\end{array}$ & 0.47 & & 1090 & 783 & b & $\begin{array}{l}667 \\
* *\end{array}$ & 410 & $a b$ \\
\hline
\end{tabular}

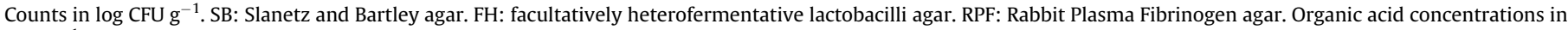

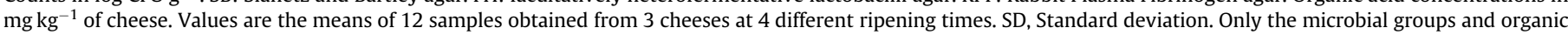

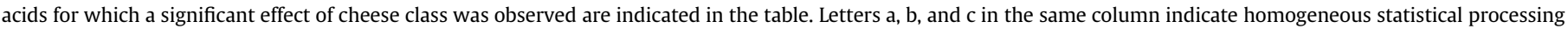

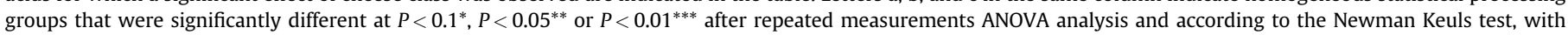
$\mathrm{a}<\mathrm{b}<\mathrm{c}$. NS, non significant. 
control cheeses (experiments 1 and 2) but only putrescine, cadaverine, and tyramine were detected at concentrations above the quantification limit (defined as three times the detection limit). Tyramine was found in equivalent amounts $\left(\sim 0.3 \mathrm{mmol} \mathrm{kg}^{-1}\right.$ cheese dry matter) in the assay and control cheeses of experiments 1 and 2 (results not shown). For cadaverine, cheeses manufactured with $H$. alvei B16, K. oxytoca 927 and to a lower extent, those manufactured with $H$. venusta 4C1A or $M$. morganii 3A2A contained significantly higher concentrations than control cheeses (Table 3 ). For putrescine, the only cheeses containing statistically higher amounts of putrescine $\left(1.53 \mathrm{mmol} \mathrm{kg}^{-1}\right.$ cheese dry matter as average) in comparison to control cheeses were those manufactured with $H$. alvei B16.

Fig. 2 shows the evolution of cadaverine and putrescine concentrations and of the free amino acid index during ripening in cheeses inoculated with the $4 \mathrm{BA}$-producing strains (experiment 2 ). Cadaverine was produced from day 1 and its concentration then increased at a fairly constant rate until day 28 (Fig. 2A). Observed differences in cadaverine concentration between cheeses elaborated with different Gram-negative strains, were constant all along the ripening process. By contrast, in cheeses manufactured with $H$. alvei, putrescine concentration increased slowly until day 7 and then increased at a similar rate as cadaverine (at least between day 8 and 28).

The evolution of the free amino acids index was roughly parallel to cadaverine production regardless of the Gram-negative strain (Fig. 2B). On day 1, phenylalanine $\left(\sim 0.30 \mathrm{mmol} \mathrm{kg}^{-1}\right)$ was the major FAA in all cheeses, followed by threonine, arginine and glutamic acid (data not shown). Histidine, leucine and tyrosine were detected as traces $\left(<0.1 \mathrm{mmol} \mathrm{kg}{ }^{-1}\right)$, whereas lysine, and ornithine were not detected. By contrast, after 28 days of ripening, lysine was the major FAA in control cheeses (Table 3), followed by leucine, phenylalanine, alanine, glutamic acid and ornithine. Low amounts of histidine and arginine were detected, whereas tyrosine was not detected. Lysine concentration was significantly lower in cheeses inoculated with $H$. alvei or $K$. oxytoca ( 1.40 and $1.28 \mathrm{mmol} \mathrm{kg}^{-1}$ respectively) than in control cheeses $\left(4.07 \mathrm{mmol} \mathrm{kg}^{-1}\right.$ ) (Table 3$)$. In addition, ornithine was not detected in cheeses inoculated with $\mathrm{H}$. alvei, while it was present in concentrations above $1.14 \mathrm{mmol} \mathrm{kg}^{-1}$ in the other cheeses analyzed.

\section{Discussion}

Enterobacteriaceae counts in cheese usually reach a peak during the first week of ripening. After this period, counts may decrease with time, depending on Enterobacteriaceae species, cheese type and cheese part (core or surface) (Morales et al., 2004; Nuňez et al., 1985;
Tornadijo et al., 2001). In our work, most tested Enterobacteriaceae reached high counts $\left(>6 \log \mathrm{CFU} \mathrm{g}{ }^{-1}\right.$ ) at day 1 in the model cheese core. The relative evolution during ripening of $K$. oxytoca and $H$. alvei was similar to that described by Tornadijo et al. (2001) in the core of San Simón pressed cheese made from raw milk. In our model cheeses as in San Simón cheese, $K$. oxytoca was predominant up to 2 weeks, its level then decreasing slightly, while $H$. alvei increased in proportion from week 2 up to the end of ripening. $H$. alvei has also been found dominant among Gram-negative bacteria in ripened Alberquilla hard cheese (Abriouel et al., 2008). In our work, C. freundii was present until the end of ripening in our model cheese as observed in Saint-Nectaire uncooked pressed cheese (Delbes et al., 2007), though it was not detected beyond the first week in San Simón cheese (Tornadijo et al., 2001). We observed that the levels of $H$. venusta and $M$. morganii decreased after 18 days in the model cheese, possibly due to antagonistic interactions with microbial populations in the technological consortium. Finally, Chryseobacterium sp. (Pi18) and S. maltophilia (PCAi D6.5), which were isolated from Saint-Nectaire cheese and raw milk respectively, did not seem to be able to establish themselves in the model cheese. But in the strain collection studied by Coton et al. (2012), Chryseobacterium and Stenotrophomonas were among the most frequent genera found, mainly in milk but also in uncooked pressed cheese core samples. The culture and storage conditions of the pure strains prior to their use for cheese-making may have been unfavorable to their adaptation and growth in the model cheese. Also, the limited ten-species consortium may have been less favorable to colonization by these strains than a more complex microbial community such as those of raw milk cheese. In particular, Mounier et al. (2008), showed that bacterial development on the surface of smear cheeses was affected by the yeast species present. In that instance, the Grampositive Leucobacter sp. grew only in cheeses containing the yeast Geotrichum candidum, while $H$. alvei dominated the bacterial flora regardless of the yeast species present.

On the other hand, Gram-negative bacteria may also interact positively or negatively with the other micro-organisms in the consortium. Counts of $A$. arilaitensis, Brevibacterium aurantiacum and $H$. alvei significantly decreased in the presence of $P$. vulgaris (UCMA 3780) in a smear-type model cheese (Deetae et al., 2009a). In the core of our model cheese, the same P. vulgaris strain slightly reduced the counts of $S$. equorum and $L b$. plantarum. Several other Gram-negative strains among those that reached the highest counts ( $C$. freundii, $M$. morganii, $K$. oxytoca) also slightly affected the development of the consortium micro-organisms and organic acid production in the model cheese. However, since freezing the cheese samples prior to analysis could have altered the balance between culturable strains, it can not be excluded that the effect of

Table 3

Concentrations of biogenic amines and amino acids in cheeses inoculated with Gram-negative bacterial strains after 28 days of ripening (experiments 1 and 2 ).

\begin{tabular}{|c|c|c|c|c|c|c|c|c|c|c|c|c|c|c|}
\hline \multirow[t]{3}{*}{ Species } & \multirow[t]{3}{*}{ Strain } & \multirow[t]{3}{*}{ BA production in vitro from Coton et al., 2012} & \multicolumn{3}{|l|}{ BA } & & & & \multicolumn{6}{|c|}{ Amino acids } \\
\hline & & & \multicolumn{3}{|c|}{ Cadaverine } & \multicolumn{3}{|c|}{ Putrescine } & \multicolumn{6}{|c|}{ Mean $^{\mathrm{a}}$} \\
\hline & & & Mean $^{\mathrm{a}}$ & Min. & Max. & Mean $^{\mathrm{a}}$ & Min. & Max. & $\operatorname{Arg}$ & Hist & Leu & Lys & Orn & Phe \\
\hline C. freundii & UCMA 4217 & Cad (15.1). IsoP (8.9). His (5.8). Tyr (0.1). Put (0.6) & $0.04^{\mathrm{a}}$ & 0.03 & 0.04 & $0.13^{\mathrm{a}}$ & 0.02 & 0.20 & nd & nd & nd & nd & nd & nd \\
\hline H. alvei & B16 & Cad (14.6). Isop (8.4). His (6.0). Phe (1.1). Put (0.7). Try (0.3) & $0.81^{\mathrm{b}}$ & 0.68 & 0.94 & $1.53^{\mathrm{b}}$ & 0.65 & 2.18 & 0.33 & 0.37 & $2.02^{\mathrm{a}}$ & $1.40^{\mathrm{a}}$ & $0.00^{\mathrm{a}}$ & $2,52^{\mathrm{a}}$ \\
\hline P. vulgaris & UCMA 3780 & Cad (0.1). Isop (0.5). His (0.1). Phe (0.1). Put (1.0). Try (0.7) & $0.02^{\mathrm{a}}$ & 0.02 & 0.03 & $0.03^{\mathrm{a}}$ & 0.02 & 0.03 & nd & nd & nd & nd & nd & nd \\
\hline H. venusta & $4 \mathrm{C} 1 \mathrm{~A}$ & Cad (12.2). His (7.4). IsoP (6.8). Phe (1.2). Put (1.2). Try (0.6) & $0.53^{\mathrm{b}}$ & 0.42 & 0.67 & $0.09^{\mathrm{a}}$ & 0.06 & 0.14 & 0.60 & 0.66 & $2.40^{\mathrm{b}}$ & $3.32^{\mathrm{b}}$ & $1.48^{\mathrm{b}}$ & $3,12^{\mathrm{b}}$ \\
\hline M. morganii & $3 \mathrm{~A} 2 \mathrm{~A}$ & Cad (14.4). His (8.8). IsoP (8.6). Put (1.4). Phe (1.6). Try (0.7) & $0.56^{\mathrm{b}}$ & 0.42 & 0.65 & $0.11^{\mathrm{a}}$ & 0.05 & 0.18 & 0.79 & 0.55 & $1.95^{\mathrm{a}}$ & $4.14^{\mathrm{b}}$ & $1.14^{\mathrm{b}}$ & $2,45^{\mathrm{ab}}$ \\
\hline K. oxytoca & 927 & Cad (12.1). IsoP (0.4) & $0.74^{\mathrm{b}}$ & 0.47 & 1.05 & $0.02^{\mathrm{a}}$ & 0.01 & 0.03 & 0.70 & 0.66 & $2.67^{\mathrm{b}}$ & $1.28^{\mathrm{a}}$ & $1.90^{c}$ & $2,52^{\mathrm{ab}}$ \\
\hline Control & & & $0.01^{\mathrm{a}}$ & 0.00 & 0.02 & $0.02^{\mathrm{a}}$ & 0.01 & 0.03 & 0.62 & 0.52 & $2.08^{\mathrm{a}}$ & $4.07^{b}$ & $1.50^{\mathrm{b}}$ & $2,05^{a}$ \\
\hline
\end{tabular}

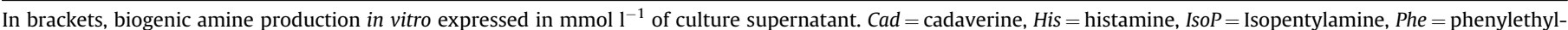
amine, Put = putrescine, Try = tryptamine.

In-core concentrations of biogenic amines and amino acids are expressed in mmol kg${ }^{-1}$ of cheese dry matter. nd: not determined.

Results having a different superscript letter are statistically different at the $P=0.01$ level according to Newman Keuls test.

a Mean values are the means of 3 cheeses from 3 independent batches. Arg $=$ arginine, Hist $=$ histamine, Leu $=$ leucine, Lys $=$ lysine, Orn $=$ ornithine, Phe $=$ phenylalanine 

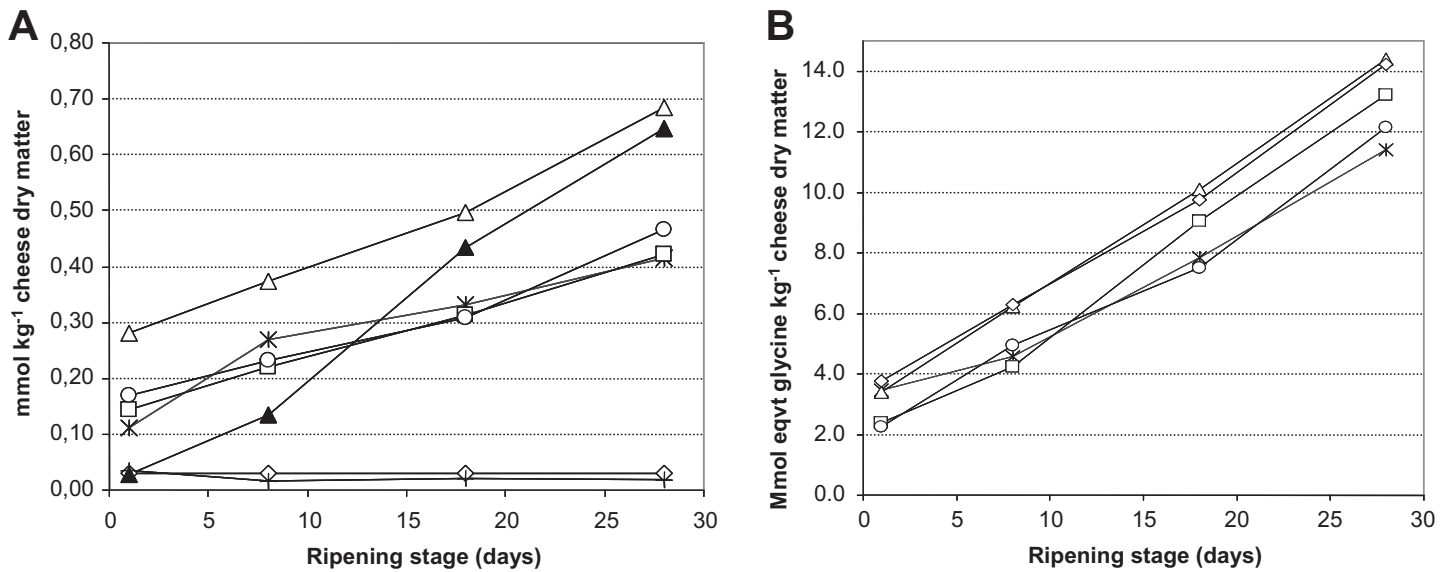

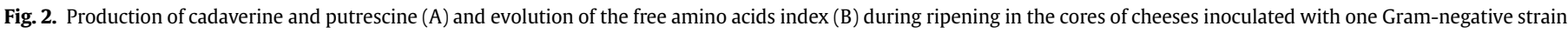

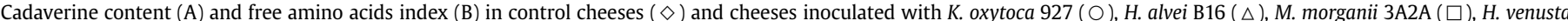

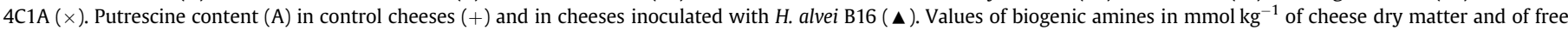

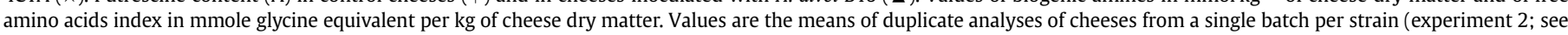
also Table 3 ) over the ripening period.

Gram-negative strains on the development of the consortium micro-organisms could be underestimated or biased.

The Gram-negative bacteria studied, especially the Enterobacteriaceae, had no significant positive nor adverse effect on the colour or odour of the model cheese, but slightly affected its texture. They also had no impact on volatile compound content, which may partly explain the lack of differences in odour. The main volatile compounds detected in all our model cheeses have also been identified in uncooked pressed Saint-Nectaire cheese made from raw milk (Sympoura et al., 2009; Picque et al., 2011). However, a lower number of volatile compounds were detected in our model cheese (26) than in Saint Nectaire cheese (37, Picque et al., 2011), probably mainly because of the less complex microflora used and the shorter ripening period ( $28 v s 56$ days, respectively). The main volatile aroma compounds detected in our model cheeses are associated with a buttery note (such as 3-hydroxy-2-butanone) or fruity notes (such as 3-methyl-1- butanol, ethyl caprylate, ethyl caproate and hexanal) (Poveda et al., 2008).

The in vitro BA-production ability of Gram-negative strains (Coton et al., 2012; Table 3) neither quantitatively nor qualitatively predicted their respective capacities for producing BA in our model cheese. Indeed, in our conditions, cadaverine and putrescine were the only BA produced in significant amounts in the model cheeses where a Gram-negative in vitro BA-producer was added. Cadaverine was produced by four of the five in vitro BA-producing strains $(H$. alvei B16, $K$. oxytoca 927, $H$. venusta 4C1A, M. morganii 3A2A). No cadaverine was produced by $C$. freundii UCMA 4217 even though this strain reached counts similar to that of $H$. venusta $4 \mathrm{C} 1 \mathrm{~A}$ or $M$. morganii $3 \mathrm{~A} 2 \mathrm{~A}$ in the cheese and has a similar in vitro producing capacity. Similarly, only $H$. alvei B16 produced significant amounts of putrescine in cheese, while the three other in vitro BA producing strains showed a similar (C. freundii UCMA 4217) or higher ( $H$. venusta $4 C 1 \mathrm{~A}$, $M$. morganii $3 \mathrm{~A} 2 \mathrm{~A}$ ) in vitro putrescine-production capacity. None of the tested Gram-negative bacteria were able to produce tyramine in large amounts in vitro. Tyramine production at similar rates in the trial and control cheeses may be explained by the presence of one or several tyramine-producing microorganisms in the technological consortium present in all the cheeses. In particular, E. faecalis strains possess the tyrosine decarboxylation pathway (Connil et al., 2002) and have been shown to produce tyramine in various cheeses (Bonetta et al., 2008; Komprda et al., 2008). No other BA produced in vitro (isopentylamine, histamine, phenylethylamine, and tryptamine) was produced in significant amount in our cheeses. No appreciable amount of histamine was produced in the cheese model by any of the 5 strains which produced it in high amount in vitro (C. freundii UCMA 4217, M. morganii 3A2A, $H$. alvei B16, P. vulgaris UCMA 3780, $H$. venusta 4C1A) (Coton et al., 2012). Even when significant, the observed cheese BA content can be considered low, as it never exceeded $100 \mathrm{mg} \mathrm{kg}^{-1}$ cheese $\left(1.1 \mathrm{mmol} \mathrm{kg}^{-1}\right.$ of putrescine, taking into account dry matter content, in cheese manufactured with $H$. alvei B16) and was lower than the level of $200-500 \mathrm{mg} \mathrm{kg}^{-1}$ cheese generally admitted as unsafe for the consumer for tyramine and histamine. Furthermore, putrescine and cadaverine don't have the same physiological impact on the consumer than histamine and tyramine, although they can be potentiators of these detrimental BA (Taylor and Lieber, 1979).

Cheese proteolysis is a dynamic process and cheese content in precursor amino acid, specific for each BA, results from a complex balance between their production during ripening and their use for BA synthesis or other metabolic pathways (García-Palmer et al., 1997). Concentrations of lysine and ornithine in 28-day old control cheeses ( $\sim 4 \mathrm{mmol} \mathrm{kg}^{-1}$ and $1.5 \mathrm{mmol} \mathrm{kg}^{-1}$ respectively) were in the same range as those found in one-month old Terrincho uncooked pressed cheeses made from raw milk ( 0.6 to $3.3 \mathrm{mmol} \mathrm{kg}^{-1}$ for lysine and 0.42 to $2.71 \mathrm{mmol} \mathrm{kg}^{-1}$ for ornithine) (Pintado et al., 2008). However, the availability of precursor amino acids did not always explain the level of BA-production in cheese by in vitro BA-producers. Indeed, amino acid decarboxylases such as those that convert L-lysine to cadaverine or L-ornithine to putrescine can be constitutive or induced (Kanjee et al., 2011; Fritz et al., 2009). In Escherichia coli and other Enterobacteriaceae, inducible lysine decarboxylases (LDC) are most effective under mild acid stress conditions ( $\sim \mathrm{pH} 5)$ in a lysinerich environment. In vitro at pH 5.8, the LDC of E. coli was found barely active at lysine concentrations below $0.5 \mathrm{mM}$ and fully active at levels exceeding $5 \mathrm{mM}$ (Fritz et al., 2009).

The absence of histamine in the model cheeses may be explained by the low amounts of histidine found in all assay and control cheeses. The absence of isopentylamine and 2-phenylethylamine was more surprising, especially in the cheeses inoculated with $H$. alvei B16, since their respective precursors leucine and phenylalamine were present in cheese from day 1 and reached concentrations above $2 \mathrm{mmol} \mathrm{kg}^{-1}$ in all cheeses at the end of ripening. Concentrations of putrescine in 28-day old cheeses inoculated with $\mathrm{H}$. alvei B16 ( 0.65 to $\left.2.18 \mathrm{mmol} \mathrm{kg}^{-1}\right)$ were in the same range as those found in one month-old Gouda or Maasdam cheeses made from pasteurized milk inoculated with $H$. alvei LN1 $\left(0.29\right.$ to $\left.2.0 \mathrm{mmol} \mathrm{\textrm {kg } ^ { - 1 }}\right)$ 
(Joosten, 1988), but were about half of those found in one-month old Terrincho cheeses (0.93 to $5.06 \mathrm{mmol} \mathrm{kg}^{-1}$ ) (Pintado et al., 2008). The depletion of ornithine in cheeses inoculated with $H$. alvei B16, in contrast with control cheeses which contained $1.5 \mathrm{mmol} \mathrm{kg}^{-1}$ after 28 days, suggested that this AA may be limiting for the synthesis of putrescine by this strain. Concentrations of cadaverine in cheeses inoculated with $H$. alvei B16 $\left(0.69-0.94 \mathrm{mmol} \mathrm{kg}^{-1}\right)$ were about half of those found in Gouda cheeses of the same age inoculated with H. alvei LN1 (1.6 to $2.0 \mathrm{mmol} \mathrm{kg}^{-1}$ ) as well as those found in Terrincho cheeses $\left(0.47-2.34 \mathrm{mmol} \mathrm{kg}^{-1}\right)$. Production of cadaverine by $\mathrm{H}$. alvei LN1 in Gouda cheese was likely limited by lysine availability, since the addition of lysine to give a concentration of $3.5-7.0 \mathrm{mmol} \mathrm{kg}^{-1}$ in cheese enhanced cadaverine production up to $6.9 \mathrm{mmol} \mathrm{kg}^{-1}$ (Joosten, 1988). Thus, although some lysine $\left(1.4 \mathrm{mmol} \mathrm{kg}^{-1}\right)$ was still available in cheeses inoculated with $H$. alvei B16 after 28 days of ripening, lysine concentration could have been too low for the decarboxylation to be efficient.

In addition, cheese physico-chemical characteristics and microbial composition may affect the metabolism of the different Gram-negative species and the activity of proteolytic and decarboxylating enzymes, and may be as important as precursor availability (Buňková et al., 2010; Novella-Rodrígues et al., 2003). Since such parameters can change from the cheese core to the surface, it cannot be excluded that larger amounts of BA may be produced by the tested strains in the cheese rind layer. Bunnková et al. (2010) found $30-50 \%$ more cadaverine in the edge layer than in the core of Edam cheese. Jørgensen et al. (2000) also showed that the combination of an arginine deiminase-positive lactic acid bacteria with an ornithine decarboxylase-positive $H$. alvei strain enhanced, by a $10-15$ fold factor, the production of putrescine in cold-smoked salmon. Hence, the chances of vicinity and synergistic interactions between proteolytic micro-organisms and BA producers may not be as high with the technological consortium used in our experiments than within the complex microbial community of raw milk cheese.

\section{Conclusion}

The Gram-negative bacteria studied in this work only slightly affected the microbial growth and sensory characteristics of the model cheese, although the texture of some assay cheeses was considered firmer than that of the corresponding control cheeses. Actual BA-production by Gram-negative bacterial strains has only rarely been studied in situ using real and usually aseptic food matrixes (Jørgensen et al., 2000; Veciana-Nogues et al., 2004). The present study showed that BA-production in an uncooked pressed model cheese by in vitro-producing Gram negative strains is a complex phenomenon which is only partly explained by the availability of precursor amino acids. The growth of the tested Enterobacteriaceae in cheese with a complex microbial consortium was similar to that observed in pressed cheeses made from raw milk (Tornadijo et al., 2001). However, their impact on microbial biodiversity and dynamics, as well as their potentialities and risks in terms of sensory characteristics and BA content should be further investigated within the complex microbial community of raw milk cheese for different cheese technologies.

\section{Acknowledgments}

This work was funded by the French Agence Nationale de la Recherche under ANR Gramme project n ${ }^{\circ}$ ANR-07-PNRA-010. The authors would like to thank M. Lapeyre, D. Tardieu, B. Desserre, R. Lavigne, R. Didienne (INRA UR545), A. Delile, B. Pollet (INRA UMR782) and F. Revardeau (INRA UR342) for their technical assistance.

\section{References}

Abriouel, H., Martin-Platero, A., Maqueda, M., Valdivia, E., Martinez-Bueno, M., 2008. Biodiversity of the microbial community in a Spanish farmhouse cheese as revealed by culture-dependent and culture-independent methods. International Journal of Food Microbiology 127, 200-208.

Alonso-Calleja, C., Carballo, J., Capita, R., Bernardo, A., Garcia-Lopez, M.L., 2002. Changes in the microflora of valdeteja raw goat's milk cheese throughout manufacturing and ripening. Lebensmittel-Wissenschaft und-Technologie 35, 222-232.

Bonetta, S., Bonetta, S., Carraro, E., Coïsson, J.D., Travaglia, F., Arlorio, M., 2008. Detection of biogenic amine producer bacteria in a typical Italian goat cheese. Journal of Food Protection 71 (1), 205-209.

Buňková, L., Buňka, F., Mantlová, G., Čablová, A., Sedláček, I., Švec, P., Pachlová, V., Kráčmar, S., 2010. The effect of ripening and storage conditions on the distribution of tyramine, putrescine and cadaverine in Edam-cheese. Food Microbiology $27,880-888$.

Bütikofer, U., Fuchs, D., Hurni, D., Bosset, J., 1990. Beitrag zur Bestimmung biogener Amine in Kase. Vergleich einer verbesserten HPLC mit einer IC Methode und Anwendung bei verschiedenen Kasesorten. Mitteilungen aus dem Gebiete der Lebensmitteluntersuchung und Hygiene 8, 120-133.

Callon, C., Berdagué, J.L., Dufour, E., Montel, M.C., 2005. The effect of raw milk microbial flora on the sensory characteristics of salers-type cheeses. Journal of Dairy Science 88, 3840-3850.

Chaves-Lopez, C., De Angelis, M., Martuscelli, M., Serio, A., Paparella, A., Suzzi, G., 2006. Characterization of the Enterobacteriaceae isolated from an artisanal Italian ewe's cheese (Pecorino Abruzzese). Journal of Applied Microbiology 101, 353-360.

Connil, N., Le Breton, Y., Dousset, X., Auffray, Y., Rinc!e, A., Prévost, H., 2002. Identification of the Enterococcus faecalis tyrosine decarboxylase operon involved in tyramine production. Applied and Environmental Microbiology 68, 3537-3544.

Coton, M., Delbès-Paus, C., Irlinger, F., Desmasures, N., Le Flèche, A., Stahl, V., Montel, M.C., Coton, E., 2012. Biodiversity and assessment of potential risk factors of Gram-negative isolates associated with French cheeses. Food Microbiology 29, 88-98.

Deetae, P., Mounier, J., Bonnarme, P., Spinnler, H.E., Irlinger, F., Helinck, S., 2009a. Effects of Proteus vulgaris growth on the establishment of a cheese microbial community and on the production of volatile aroma compounds in a model cheese. Journal of Applied Microbiology 107 (4), 1404-1413.

Deetae, P., Spinnler, H.E., Bonnarme, P., Helinck, S., 2009b. Growth and aroma contribution of Microbacterium foliorum, Proteus vulgaris and Psychrobacter sp. during ripening in a cheese model medium. Applied Microbiology and Biotechnology 82, 169-177.

Delbes, C., Ali Mandjee, L., Montel, M.C., 2007. Monitoring bacterial communities in raw milk and cheese by culture-dependent and -independent 16S rRNA gene-based analyses. Applied and Environmental Microbiology 73, 1882-1891.

Denis, C., Gueguen, M., Henry, E., Levert, D., 2001. New media for the numeration of cheese surface bacteria. Lait $81,365-379$.

Ercolini, D., Russo, F., Ferrocino, I., Villani, F., 2009. Molecular identification of mesophilic and psychrotrophic bacteria from raw cow's milk. Food Microbiology 26, 228-231.

Folkertsma, B., Fox, P., 1992. Use of Cd. ninhydrin reagent to assess proteolysis in cheese during ripening. Journal of Dairy Research 59, 217-224.

Fritz, G., Koller, C., Burdack, K., Tetsch, L., Haneburger, I., Jung, K., Gerland, U., 2009. Induction kinetics of a conditional pH stress response system in Escherichia coli. Journal of Molecular Biology 393, 272-286.

García-Palmer, F.J., Serra, N., Palou, A., Gianotti, M., 1997. Free amino acids as indices of Mahón cheese ripening. Journal of Dairy Science 80, 1908-1917.

Innocente, N., Marino, M., Marchesini, G., Biasutti, M., 2009. Presence of biogenic amines in traditional salted Italian cheese. International Journal of Dairy Technology 62 (2), 154-160.

Joosten, H.M.L.J., 1988. Conditions allowing the formation of biogenic amines in cheeses. 3. Factors influencing the amounts formed. Netherlands Milk Dairy Journal 41, 329-357.

Jørgensen, L.V., Huss, H.H., Dalgaard, P., 2000. The effect of biogenic amine production by single bacterial cultures and metabiosis on cold-smoked salmon. Journal of Applied Microbiology 89, 920-934.

Kanjee, U., Gutsche, I., Ramachandran, S., Houry, W.A., 2011. The enzymatic activities of the Escherichia coli basic aliphatic amino acid decarboxylases exhibit a $\mathrm{pH}$ zone of inhibition. Biochemistry. dx.doi.org/10.1021/bi201161k.

Komprda, T., Burdychová, R., Dohnal, V., Cwiková, O., Sládková, P., Dvorácková, H., 2008. Tyramine production in Dutch-type uncooked pressed cheese from two different producers. Food Microbiology 25 (2), 219-227.

Lafarge, V., Ogier, J.C., Girard, V., Maladen, V., Leveau, J.Y., Gruss, A., DelacroixBuchet, A., 2004. Raw cow milk bacterial population shifts attributable to refrigeration. Applied and Environmental Microbiology 70, 5644-5650.

Larpin-Laborde, S., Imran, M., Bonaïti, C., Bora, N., Gelsomino, R., Goerges, S., Irlinger, F., Goodfellow, M., Ward, A., Vancanneyt, M., Swings, J., Scherer, S., Guéguen, M., Desmasures, N., 2011. Surface microbial consortia from Livarot, a French smear ripened cheese. Canadian Journal of Microbiology 57, 651-660.

Maoz, A., Mayr, R., Scherer, S., 2003. Temporal stability and biodiversity of two complex antilisterial cheese-ripening microbial consortia. Applied and Environmental Microbiology 69, 4012-4018.

Marino, M., Maifreni, M., Moret, S., Rondinini, G., 2000. The capacity of Enterobacteriaceae species to produce biogenic amines in cheese. Letters in Applied Microbiology 31, 169-173. 
Martuscelli, M., Gardini, F., Torriani, S., Mastrocola, D., Serrio, A., Chaves-López, C., Schirone, M., Suzzi, G., 2005. Production of biogenic amines during the ripening of Pecorino Abruzzese cheese. International Dairy Journal 15, 571-578.

Morales, P., Feliu, I., Fernández-García, E., Nuňez, M., 2004. Volatile coupounds produced in cheese by Enterobacteriaceae strains of dairy origin. Journal of Food Protection 67 (3), 567-573.

Mounier, J., Gelsomino, R., Goerges, S., Vancanneyt, M., Vandemeulebroecke, K., Hoste, B., Scherer, S., Swings, J., Fitzgerald, G.F., Cogan, T.M., 2005. Surface microflora of four smear-ripened cheeses. Applied and Environmental Microbiology 71, 6489-6500.

Mounier, J., Monnet, C., Vallaeys, T., Arditi, R., Sarthou, A.S., Helias, A., Irlinger, F., 2008. Microbial interactions within a cheese microbial community. Applied and Environmental Microbiology 74, 172-181.

Munsch-Alatossava, P., Alatossava, T., 2006. Phenotypic characterization of raw milkassociated psychrotrophic bacteria. Microbiological Research 161, 334-346.

Novella-Rodrígues, S., Veciana-Nogués, M.T., Izquerdo-Pulido, M., Vidal-Carou, M.C. 2003. Distribution of biogenic amines and polyamines in cheese. Journal of Food Science 68, 750-755.

Nuňez, M., Gaya, P., Medina, M., 1985. Influence of manufacturing and ripening conditions on the survival of Enterobacteriaceae in Manchego cheese. Journal of Dairy Science 68, 794-800.

Pattono, D., Grassi, M.A., Civera, T., 2008. Production of biogenic amines by some Enterobacteriaceae strains isolated from dairy products. Italian Journal of Food Science 20 (3), 411-417.

Picque, D., Leclercq-Perlat, M.N., Guillemin, H., Cattenoz, T., Corrieu, G., Montel, M.C., 2011. Impact of packaging on the quality of Saint-Nectaire cheese. International Dairy Journal 21, 987-993.

Pintado, A.I.E., Pinho, O., Ferreira, I.M.P.L.V.O., Pintado, M.M.E., Gomes, A.M.P., Malcata, F.X., 2008. Microbiological, biochemical and biogenic amine profiles of
Terrincho cheese manufactured in several dairy farms. International Dairy Journal 18, 631-640.

Poveda, J.M., Sánchez-Palomo, E., Pérez-Coello, M.S., Cabezas, L., 2008. Volatile composition, olfactometry profile and sensory evaluation of semi-hard Spanish goat cheeses. Dairy Science and Technology 88 (3), 355-367.

Schirone, M., Tofalo, R., Mazzone, G., Corsetti, A., Suzzi, G., 2011. Biogenic amine content and microbiological profile of Pecorino di Farindola cheese. Food Microbiology 28, 128-136.

Schneller, R., Good, P., Jenny, M., 1997. Influence of pasteurised milk, raw milk and different ripening cultures on biogenic amine concentrations in semi-softt cheeses during ripening. Zeitschrift für Lebensmittel-Untersuchung und -Forschung 204 265-272.

Sørhaug, T., Stepaniak, L., 1997. Psychrotrophs and their enzymes in milk and dairy products, quality aspects. Trends in Food Science and Technology 8, 35-41.

Sympoura, F., Cornu, A., Tournayre, P., Massouras, T., Berdagué, J.L., Martin, B. 2009. Odor compounds in cheese made from the milk of cows supplemented with extruded linseed and alphatocopherol. Journal of Dairy Science 92 3040-3048.

Taylor, S.L., Lieber, E.R., 1979. In vivo inhibition of rat intestinal- histaminemetabolizing enzymes. Food Cosmetic Toxicology. 17, 237-240.

Tornadijo, M.E., Garcia, M.C., Fresno, J.M., Carballo, J., 2001. Study of Enter obacteriaceae during the manufacture and ripening of San Simon cheese. Food Microbiology 18, 499-509.

Veciana-Nogues, M.T., Bover-Cid, S., Marine-Font, A., Vidal-Carou, M.C., 2004 Biogenic amine production by Morganella morganii and Klebsiella oxytoca in tuna. European Food Research and Technology 218 (3), 284-288.

Yvon, M., Berthelot, S., Gripon, J.C., 1998. Adding alpha-ketoglutarate to semi-hard cheese curd highly enhances the conversion of amino acids to aroma compounds. International Dairy Journal 8, 889-898. 